\title{
An integrative collaborative care model for people with mental illness and physical comorbidities
}

\author{
C. Ee ${ }^{1 *}$, J. Lake ${ }^{1}$, J. Firth ${ }^{1}$, F. Hargraves ${ }^{1}$, M. de Manincor ${ }^{1}$, T. Meade ${ }^{2}$, W. Marx ${ }^{3}$ and J. Sarris ${ }^{1,4^{*}}$
}

\begin{abstract}
Background: Many individuals with mental health problems have comorbid physical conditions, or may present with substance/alcohol misuse or abuse issues. This results in complex treatment challenges that may not be adequately addressed by a model of care that is solely delivered by an individual clinician using a sole intervention. Mainstream pharmacotherapeutic treatment of mental health problems often have limited effectiveness in completely resolving symptoms, and may cause adverse side effects. Adjunctive treatment approaches, including nutraceuticals, lifestyle and behaviour change interventions, are widely used to assist with treatment of mental health problems. However, whilst these can be generally safer with fewer side effects, they have varying levels of evidentiary support. These circumstances warrant reframing the current treatment approach towards a more evidence-based integrative model which may better address the real-world challenges of psychiatric disorders and comorbid physical conditions. In essence, this means developing an integrative model of care which embodies an evidence-informed, personalized stepwise approach using both conventional pharmacological treatments alongside novel adjunctive treatments (where applicable) via the application of a collaborative care approach.
\end{abstract}

Discussion: In order to inform this position, a brief review of findings on common patterns of comorbidity in mental illness is presented, followed by identification of limitations of conventional treatments, and potential applications of integrative medicine interventions. Advantages and challenges of integrative mental health care, collaborative models of care, review of research highlights of select integrative approaches, and comment on potential cost advantages are then discussed.

Summary: We propose that a collaborative care model incorporating evidence-based integrative medicine interventions may more adequately address mental health problems with comorbid medical conditions. Robust research is now required of such a model, potentially within an integrative clinical practice.

Keywords: Integrative model, Collaborative care, Mental health, Comorbidity, Integrative medicine, Complementary medicine, Lifestyle medicine

*Correspondence: c.ee@westernsydney.edu.au; J.Sarris@westernsydney.edu. au

1 NICM Health Research Institute, Western Sydney University, Penrith, NSW 2751, Australia

${ }^{4}$ Professorial Unit, Department of Psychiatry, The University of Melbourne, Melbourne, Australia

Full list of author information is available at the end of the article

\section{The current challenge}

It is estimated that 300 million people globally are affected by depression, in addition to 60 million by bipolar affective disorder, and 23 million by schizophrenia [1]. Of concern, treatment for mental health problems is inadequate, with between 35 and $50 \%$ of people with mental disorders in high-income countries not receiving mental health treatment [2]. In low- and middle-income

c) The Author(s) 2020. This article is licensed under a Creative Commons Attribution 4.0 International License, which permits use, sharing, adaptation, distribution and reproduction in any medium or format, as long as you give appropriate credit to the original author(s) and the source, provide a link to the Creative Commons licence, and indicate if changes were made. The images or other third party material in this article are included in the article's Creative Commons licence, unless indicated otherwise in a credit line to the material. If material is not included in the article's Creative Commons licence and your intended use is not permitted by statutory regulation or exceeds the permitted use, you will need to obtain permission directly from the copyright holder. To view a copy of this licence, visit http://creativeco mmons.org/licenses/by/4.0/. The Creative Commons Public Domain Dedication waiver (http://creativecommons.org/publicdomain/ zero/1.0/) applies to the data made available in this article, unless otherwise stated in a credit line to the data. 
countries this figure is as high as $85 \%$ [3]. Further, delays in receiving care are common. On average, it takes almost 10 years to obtain treatment after symptoms of depressed mood begin, and more than two-thirds of depressed individuals never receive adequate care [4]. Between 10 and 20 million people with depression attempt suicide every year, and approximately one million will complete suicide [4]. Mental disorders such as depression, anxiety and schizophrenia are the largest cause of disability and economic burden across many countries [4].

Large population surveys of different world regions consistently show high prevalence of mental illness with other comorbid conditions [5] where they can be a precursor or a consequence of conditions such as major non-communicable conditions such as cardiovascular disorders, diabetes, respiratory conditions and cancer [4]. Actual rates of comorbidity in world populations are difficult to estimate and reported rates reflect disparate criteria used in different countries to classify symptoms into disorders [6].

Urgent unmet treatment needs in people with depression led the World Health Organization in 2016 to declare depression the leading cause of disability worldwide [7]. The need for treatment approaches that encompass both mental and physical domains to improve overall wellbeing and health of those experiencing depression has never been more evident. Achieving this requires adopting a more comprehensive evidence-based treatment model to address mental and physical health in a more integrated manner. This paper provides such a framework, firstly discussing the general background on medical comorbidity with mental illness, the current limitations of conventional mental healthcare, before outlining the potential benefits of integrative collaborative care, and providing a proposed model with clinical considerations for real-world application.

\section{Mental health disorders and physical comorbidity}

Mental illnesses are frequently comorbid with a range of physical medical disorders in all age groups, and significantly impact the clinical course and response to treatment $[8,9]$. In severe mental illness (SMI), which includes schizophrenia and other psychotic disorders and bipolar affective disorder, frequent physical co-morbidity results in a higher hospital admission rate for physical disorders than the general population, and a substantially lower life expectancy [10]. On average, people with SMI die twenty-five years earlier than the general population, with the primary cause of death being pathological illness rather than suicide [11]. In general, mental illnesses are associated with an increased risk of cardiometabolic conditions such as obesity, diabetes and cardiovascular disease at a rate 1.4-2.0 times higher than in the general population [9].

The reasons for co-morbidity are complex and intertwined, and include social determinants of health, lifestyle factors, sleep disturbance, and medication sideeffects $[9,10]$. Genetic studies also suggest that people with schizophrenia are more likely to develop metabolic syndrome, even if antipsychotic-naïve, although the evidence is inconsistent [11]. Likewise, physical comorbidities with depression are understood to be due to genetic and epigenetic factors [12]. It is well-established that antipsychotics have an orexigenic effect and can increase weight and promote dyslipidemia [13] as well as have a range of toxicities on haematological, neurological, and gastrointestinal systems [11]. Further, the rates of undertreatment of cardiovascular risk factors in people with schizophrenia are high [14]. Furthermore, many of the pathophysiological pathways implicated in mental disorders are also common in chronic diseases. These include heightened inflammatory [15] and oxidative [16] stress responses, mitochondrial dysfunction, and gut microbiota [17] dysbiosis. $[15,17,18]$ and the association between depression and physical comorbidities such as cancer is likely due to shared aberrations in these pathways [19]. Older adults appear to be at greater risk of physical and mental multimorbidity. Last, poor mental health often results in lower capacity to implement lifestyle interventions [20], lower patient activation and engagement [21], social isolation (often due to stigma) [22] and low social capital [23], which increase the risk of chronic non-communicable disorders. Table 1 below describes some of the common comorbidities between mental health and physical conditions.

\section{Limitations of conventional mental health care}

Whilst there is substantial research to show that pharmacologic treatments can reduce the symptoms of major depressive disorder, bipolar disorder, and other psychiatric disorders, the evidence for complete and sustained remission from these treatments alone is limited [36-43]. Further, as many as one half of individuals being treated for psychiatric disorders fail to respond or respond only partially to psychotropic medications and are often labelled as "treatment-resistant" or "nonresponders" [44-46]. Poor treatment outcomes due to limited efficacy of antidepressants, mood stabilizers, antipsychotics, and other psychotropic medications, alongside the socioeconomic, physical and environmental factors discussed in the section above, can result in long-term impaired functioning, work absenteeism, and losses in productivity [47-51]. Other biological therapies include electro-convulsive therapy, which is reserved for severe and complex depression 
Table 1 Mental health conditions and physical co-morbidities

\begin{tabular}{|c|c|}
\hline Co-morbid condition & \\
\hline Cancer & $\begin{array}{l}\text { One third of people with cancer meet diagnostic criteria for at least one psychiatric disorder, including major depressive disor- } \\
\text { der, anxiety disorders, adjustment disorders, sleep disorders and delirium [24]; prevalence is higher in people with advanced } \\
\text { cancer } \\
\text { Comorbid mental disorders reduce quality of life, interfere with treatment adherence and, in the case of depression, may affect } \\
\text { the rate of cancer progression [25] } \\
\text { However, people with schizophrenia are at lower risk of having cancer (OR 0.76) [26] } \\
\text { People with cancer who have pre-existing depression have higher all-cause, cancer-related and non-cancer related mortality } \\
\text { [27] }\end{array}$ \\
\hline $\begin{array}{l}\text { Chronic obstructive } \\
\text { pulmonary disease }\end{array}$ & $\begin{array}{l}\text { Individuals with chronic obstructive pulmonary disease (COPD) are at increased risk of depressed mood and anxiety compared } \\
\text { to the general population [28] }\end{array}$ \\
\hline Cardiovascular disease & $\begin{array}{l}\text { Depressed mood and cardiovascular diseases frequently occur together with an estimated } 20 \text { to } 45 \% \text { of individuals with heart } \\
\text { disease and depression and those who have had a heart attack } 3 \text { times more likely to be depressed compared to the general } \\
\text { population [29] } \\
\text { Relationship between heart disease and depressed mood is multifactorial. Risk factors include dysfunction of the hypotha- } \\
\text { lamic-pituitary-adrenal axis, increased pro-inflammatory activity, reduced omega-3 fatty acids, reduced heart rate variability, } \\
\text { smoking, physical inactivity and low self-esteem [29] } \\
\text { Hypertension is one of the most common co-morbid conditions in people with schizophrenia [26]. People with schizophrenia } \\
\text { have between a 1.2-3.6-fold increased risk of coronary artery disease, and up to 3-fold increase in sudden cardiac death than } \\
\text { the general population [11] }\end{array}$ \\
\hline Diabetes & $\begin{array}{l}\text { Depression is associated with a } 60 \% \text { increase in diabetes and diabetes with } 15 \% \text { increase in depression [4] } \\
\text { People with schizophrenia have an increased risk of diabetes (OR 2.23) [26] } \\
\text { People with diabetes who report severe symptoms of depressed mood tend to be less compliant with treatment [30], and are } \\
\text { at higher risk of coronary heart disease [31] } \\
\text { Chronic hypoglycaemia caused by excess insulin secretion is often associated with intense anxiety and panic attacks [32] }\end{array}$ \\
\hline Arthritis & People with depression have a 34\% higher prevalence of arthritis than people without depression [33] \\
\hline Alzheimer's disease & $\begin{array}{l}\text { Depression is a risk factor for developing Alzheimer's disease (AD) and dementia symptoms [34], and treatment of depression } \\
\text { in individuals with AD can improve cognitive function and quality of life [35] }\end{array}$ \\
\hline
\end{tabular}

and carries substantial risks [52], and transcranial magnetic stimulation, which has a variable clinical response [53].

When pharmacological treatment is not effective, an addition of psychotherapy is a recommended next step in the NICE guidelines [52]. A recent Cochrane systematic review [54] based on six randomised control trials found significantly greater short term and long term reduction in depressive symptoms for those who in addition to anti-depressant received psychotherapy. Given that depression often results from an interaction between biological, psychological and societal factors, a pharmacological treatment may only influence an aspect of the presentation, leaving other factors potentially unresolved and ongoing. With comorbidity between depression and other health conditions being more common than not, it is recommended that a network approach can be used, whereby treatment is designed to change or manipulate a symptoms network through symptoms intervention (e.g. interventions to treat low mood); external triggers intervention (e.g. interpersonal conflict resolution); and network intervention (e.g. cognitive behavioural therapy to address the impact of low mood on daily functioning) [55]. Further, as there is a high level of comorbidity between depression and other conditions, transdiagnostic-based treatments are likely to be more effective [56].
Alongside this, many commonly prescribed psychotropic medications including antidepressants and antipsychotics, are associated with serious adverse effects, including weight gain, metabolic syndrome, increased risk of diabetes and coronary artery disease, neurologic disorders, and sudden cardiac death [57], thereby in some cases being responsible for actually causing iatrogenic physical comorbidity. Further, although existing clinical guidelines provide some direction with regard to physical comorbidities and mental health [58-61], this guidance is generally limited to modifying treatment according to physical disabilities [58], prescription of metformin and statins for cardiovascular risk and obesity, and recommending cardiometabolic monitoring, close liaison with primary care, and lifestyle interventions [59-61].

\section{Non-pharmacological approaches to managing comorbidity}

There is a clear need for clinical approaches to healthcare that have the potential to improve both mental and physical health concurrently. In the context of the limitations of available treatment choices for mental health problems, increasing numbers of people are seeking concurrent treatment for their mental health from conventional medical and other practitioners utilizing approaches such as lifestyle medicine (e.g. diet, exercise, mindfulness 
practice), nutraceutical treatments, and complementary therapies [62, 63]. Whilst it is difficult to establish clear distinctions between these approaches, this may involve three key platforms, integrated with "conventional" mental health care, such as the appropriate prescription of psychotropic drugs and provision of psychological therapies e.g. cognitive behavioural therapy and medical care for co-morbidities. Further, 'collaborative care' approaches are emerging as a model of care that could improve outcomes in people with mental health disorders with physical co-morbidities [64]. Figure 1 below describes the platforms in our model.

1 Multi-component behaviour change lifestyle interventions combining exercise, diet, sleep, alcohol reduction, and smoking cessation interventions to improve lifestyle risk factors for both physical and mental illness $[9,65]$.

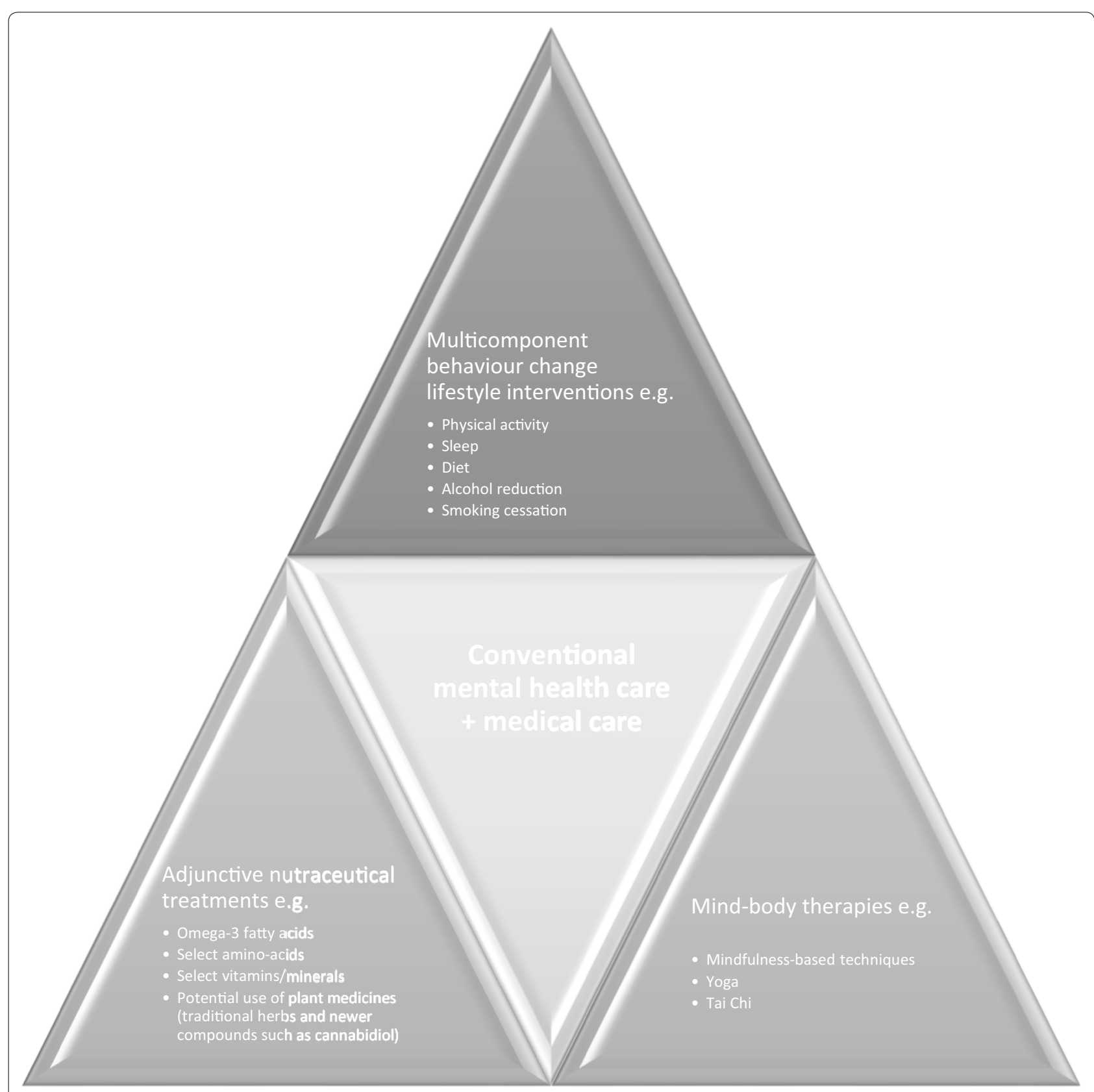

Fig. 1 An integrative model of healthcare 
2 Adjunctive nutraceutical treatments such as omega-3 s, select amino-acids and vitamin compounds, along with potential use of plant medicines (including traditional herbs such as St. John's wort and newer plant-based compounds such as cannabidiol/CBD) [66, 67].

3 Mind-body therapies such as yoga, tai chi, and mindfulness-based interventions [68].

\section{Potential role of lifestyle medicine and nutraceuticals}

A number of lifestyle and integrative therapies have been evaluated for effectiveness as adjunctive therapies for mental health conditions such as depression and anxiety, and some show promise (see Table 2). These therapies have the potential to improve both mental and physical health, and therefore may improve health outcomes for people with mental and physical co-morbidities. In particular, there is a strong evidence base for the use of physical activity as a treatment for SMI, common mental disorders, ADHD and PTSD, as demonstrated within a recent meta-review of meta-analyses of RCTs; showing comparable efficacy across all of these conditions [69]. Whereas the evidence for dietary interventions is more nascent, there are now meta-analyses of RCTs showing small but statistically significant reductions in depressive symptoms from dietary interventions [70]. Interestingly however, the benefits so far seem to mostly be observed in predominantly female samples. Similarly, smoking cessation interventions can confer notable improvements for both physical and mental health in those with psychiatric disorders; as smoking is a leading cause of premature mortality in psychiatric populations, and reducing smoking also attenuates symptoms of depression and anxiety in those with mental illness [71]. The evidence for effectiveness of mind-body therapies such as yoga and mindfulnessbased interventions for both mental and physical health is more preliminary in nature, however the literature is promising. There is the potential for mind-body therapies to impact positively not only on mental health symptoms such as depressive and anxiety symptoms, but also assist with adherence to behaviour change due to a greater acceptance of the discomforts of calorie restriction and increasing physical activity [72-75]. Most of these therapies have the advantages of being relatively low-risk with the exception of nutraceutical supplements which have the potential for more adverse effects and supplement-drug interactions. They can be integrated into the care of a person with mental and physical co-morbidities as adjunctive therapy.

\section{Collaborative care}

Collaborative care is a complex intervention that aims to foster close working relationships between members of a treating team, often involving the integration of primary and secondary health care, in order to provide high quality care to a patient and improve both mental and physical health outcomes. There is no single agreed on definition of collaborative care, however in essence collaborative care involves more than one health care professional providing care to the patient, and systematic efforts to improve communication and teamwork within the treating team. Apart from a multidisciplinary team, other components of collaborative care may include case management or coordination, patient education, provider education, systematic follow-up of the patient, use of guidelines and algorithms, psychological interventions, and shared decision-making with patients [10].

The integration of physical and mental healthcare providers in a collaborative model can improve the quality of care that is provided, and address both physical as well as mental health needs of the patient [76]. Outcomes studies support that collaborative care models are more effective than conventional care models for treatment of depressed mood, anxiety disorders, bipolar disorder, and schizophrenia [77-82] as well as treatment of individuals with comorbid physical conditions [10, 81, 83]. Collaborative care models also may reduce health care disparities in patients from different socioeconomic and ethnic backgrounds, thereby improving access to care [84-87].

People with depression or other serious health problems or comorbid presentations, often respond better and more rapidly when managed by a team of practitioners using collaborative care models. Collaborative care is more cost-effective than usual care in all categories measured, including medication costs and inpatient, outpatient, and mental health specialty care [88], as well as for the management of depressed patients with comorbid medical disorders [83, 89], severe anxiety disorders [90] and serious chronic mental illness [91-93]. Finally, both providers and patients report high levels of satisfaction with the management of depressed mood in collaborative care settings $[78,94]$. The next step in advancing true collaborative care, is in the utilization of evidence-based integrative modalities within this treatment model.

\section{Integrative medicine}

Integrative medicine is defined as a practice that “... reaffirms the importance of the relationship between practitioner and patient, focuses on the whole person, is informed by evidence, and makes use of all appropriate therapeutic and lifestyle approaches, healthcare professionals and disciplines to achieve optimal health and healing" [95] Approaches used in integrative mental 


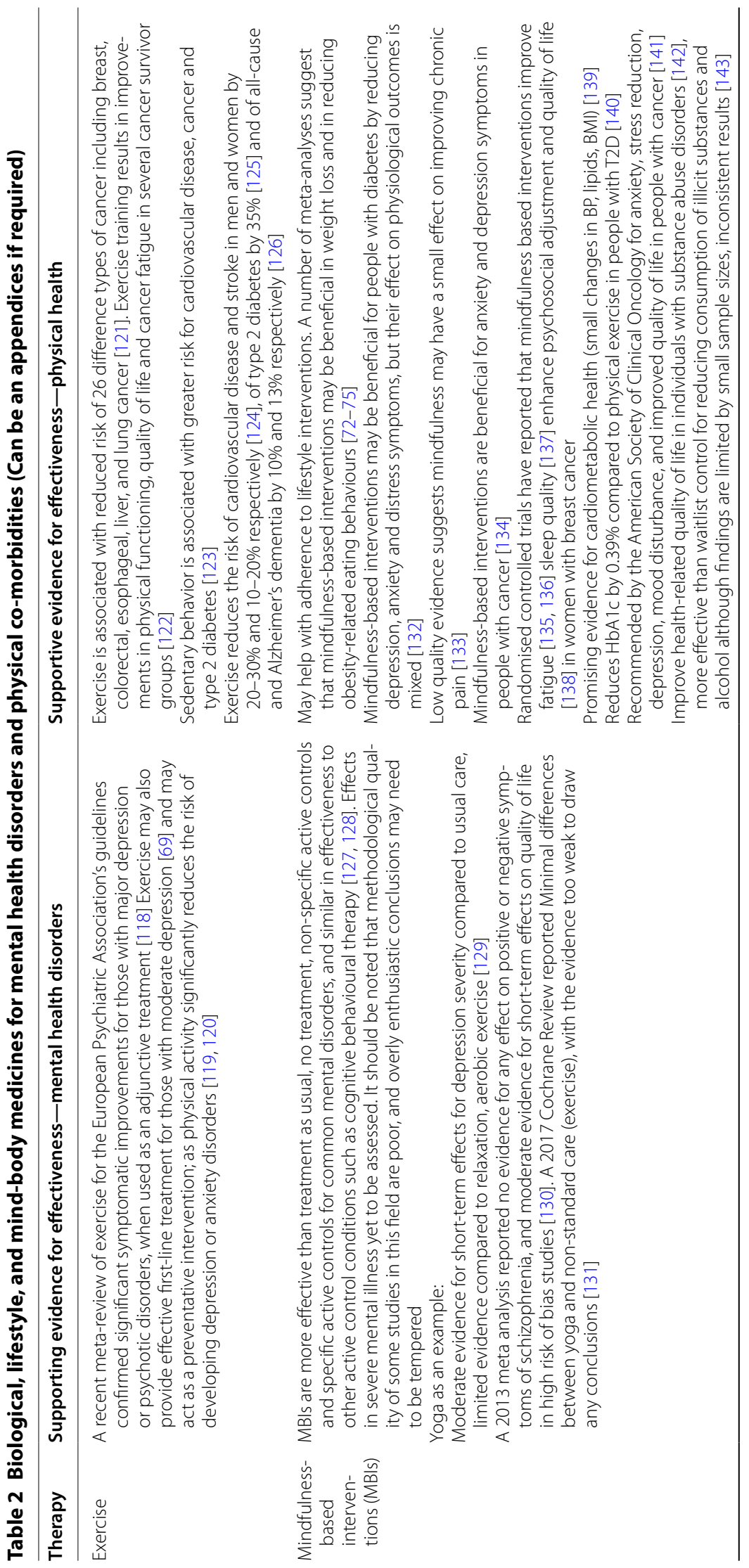




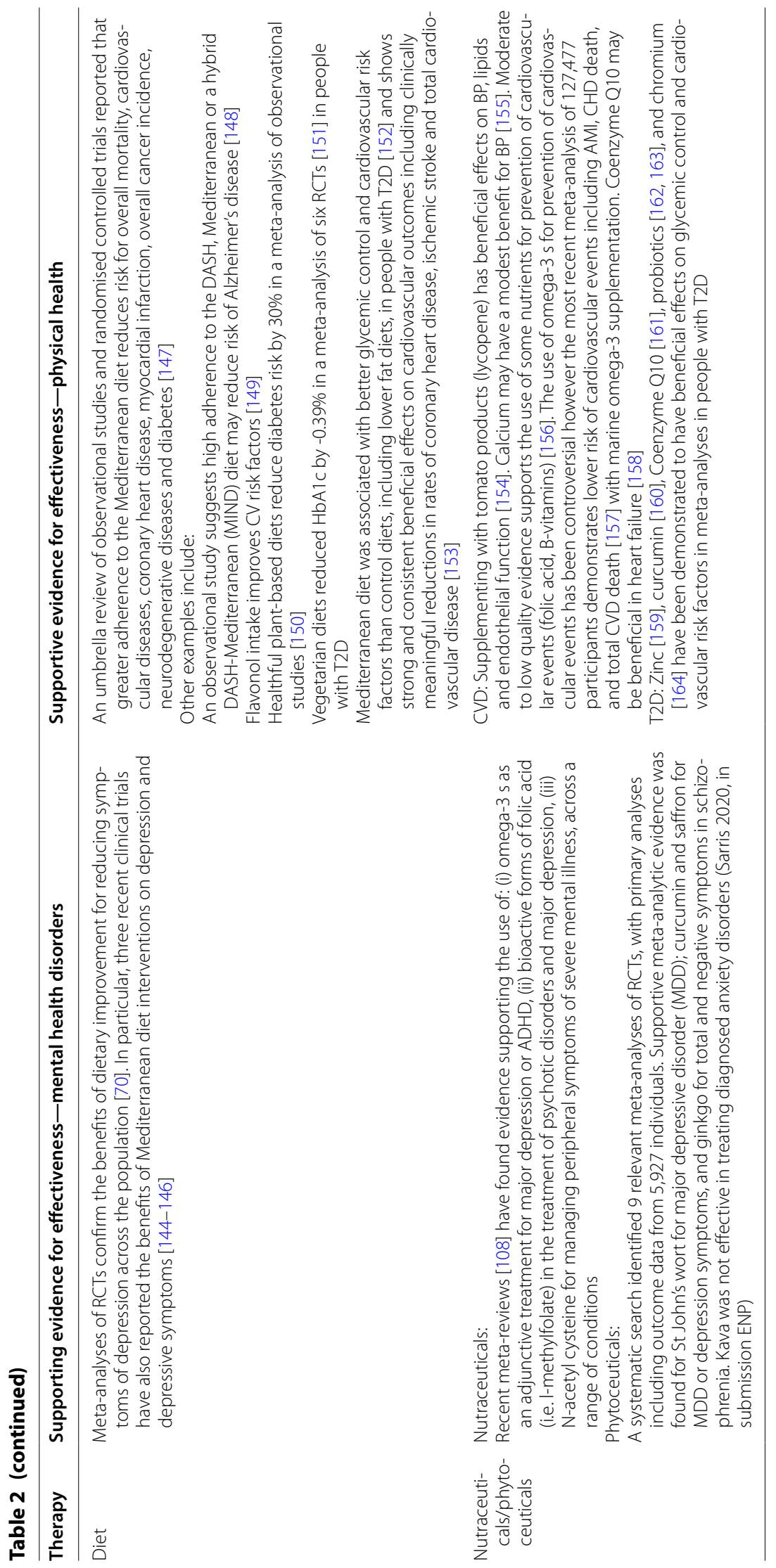


health care may include prescription medication, psychotherapy, psychological treatments, nutraceutical and herbal supplements, mind body therapies, and positive lifestyle changes such as diet, exercise, and sleep hygiene.

Integrative mental health care may result in significant cost-savings. Findings from economic modelling research suggest that whilst a more integrative approach may initially cost more, down-stream savings can be achieved when integrative strategies yield positive long-term outcomes [96, 97]. Similarly, systematic reviews of economic modelling studies on comparative cost-effectiveness of conventional versus integrative treatments of many health conditions (including mental illness), suggest that integrative treatments are cost-effective, and in some cases, provide cost savings [42]. Individual lifestyle interventions have also demonstrated cost-effectiveness [98, 99]. Finally, higher up-front costs of integrative treatment approaches may be potentially offset by improved work productivity and increased future Quality Adjusted Life Years (QALYs) [96]. Further, cost-effectiveness of individual lifestyle interventions has also been demonstrated $[98,99]$.

Integrative medicine lends itself well to a collaborative care model, given the number of different modalities that could play a role in care of the patient, and the holistic approach that is involved. We propose a model for integrative collaborative care for people with mental and physical co-morbidities.

The term integrative medicine should be distinguished from integrated care, which has many definitions and associated models [100], but in this context may refer to vertical integration of primary and secondary care services.

\section{An integrative collaborative care model}

In this section we develop practical clinical methods for integrative management of complex patients with high comorbidity in collaborative care settings. These methods are informed by qualitative research we conducted while designing the model of care for Australia's first academic integrative healthcare centre [101, 102], and a health forum which was undertaken in Sydney in April 2019 to inform the direction of research arising from a White Paper on depression and co-morbidity commissioned by Western Sydney University [103]. To the best of our knowledge, no such model has been described in the literature. This model lends itself well to a primary care setting, as primary care health professionals (general practitioners/family physicians) are experts in provision of whole-person, comprehensive and person-centred care [104]. It is not uncommon for primary care practices to include a range of allied health and integrative medicine practitioners on-site, and this would serve as an ideal opportunity to build a collaborative care model. Alternatively, a community health setting, or secondary care setting, with appropriate integration with primary care and allied health, would also work well.

\section{Triage and assessing urgency}

Initially, a clear written policy and procedure for triaging and managing psychiatric emergencies and psychological distress, including assessment and management of suicide risk, is required. This policy and procedure should be available to all members of the care team, as immediate risk from worsening mental health may be uncovered in consultations with allied health and complementary therapy practitioners. Similarly, clear written policies and procedures (along with necessary training and updating of skills) are required for triaging and managing medical emergencies such as acute myocardial infarction, stroke and diabetic ketoacidosis. This can include the identification of physical "red flags" in history, such as sudden onset chest pain on exertion, that should trigger urgent medical review.

\section{Creating a comprehensive care plan}

In collaborative healthcare models, a comprehensive plan for individual patient care is developed by the healthcare team in partnership with the patient and their family and/or carers. This history may be taken in collaboration by several members of the healthcare team. There should be a designated team member who assumes responsibility for creating and disseminating the care plan. This could be the primary care practitioner, care coordinator, or mental health clinician (e.g. psychologist/psychiatrist).

\section{Clinical history}

A collaborative care team can contribute to different aspects of history taking and assessment which should comprise a thorough documentation of all previous and current mental health, substance use and co-morbid physical problems. The process of onboarding and intake should be outlined clearly in policies and procedures, including which team member initially consults with the patient. Relative priorities are subsequently assigned to ongoing problems with respect to the amount of distress or impairment in functioning they cause, and prioritisation is done in collaboration with the patient, family, carers, and other health professionals. Some useful tools to facilitate this include the Measure Yourself Concerns and Wellbeing (MYCAW) questionnaire [105], What Matters Index, or the Bubble Diagram [106, 107]. Further formal assessment may be required to clarify physical and psychiatric diagnoses. 


\section{Lifestyle habits}

The key in providing excellent healthcare to people with mental health conditions and physical co-morbidities is the application of lifestyle medicine. A comprehensive lifestyle and social history should be obtained, including current and past physical activity levels, current ability to perform physical activity, preferences for physical activity options; intake of fruits, vegetables, processed foods, takeaway, alcohol, and soft drinks; availability of fresh food; sleep history; a social history including cultural background, employment, family and home support, social networks, ability to pay for treatment; and individual preferences and values regarding treatment. This information is crucial to obtain as ability to pay and personal preferences may impact on the treatment that is selected. Further, ability to perform physical activity needs to be factored into lifestyle recommendations, as this may be impacted upon by physical comorbidities e.g. poor mobility and balance from Parkinson's disease. Last, availability of fresh food is limited in some geographical areas (often referred to as "food deserts") therefore impacting on ability to make positive dietary changes. A comprehensive lifestyle history is facilitated by the involvement of team members with the relevant expertise, i.e. exercise physiology and dieticians.

\section{Informed decision making}

Informed decision making involves identifying appropriate treatment modalities for consideration, with a discussion around the potential risks and benefits of available treatments (conventional psychiatric/psychosocial and medical, as well as adjunctive integrative therapies) in the process of obtaining informed consent. The process of informed decision making is enhanced by availability of guidelines, written clinical pathways and evidence syntheses. Patients and practitioners can only make this decision after considering the best available evidence on the proposed therapies, the potential risks (including supplement-drug interactions) and the patient's individual circumstances and preferences. This discussion is especially important when considering complementary and integrative therapies, where evidence for efficacy may be emerging or scarce. The discussion should be documented in the medical record. The risks of treatment include the financial cost, which may be prohibitive in the case of lack of insurance and ability to pay. In these cases, group-based care may be helpful. Where nutraceuticals and herbal supplements are prescribed, potential adverse effects and supplement-drug interactions should be screened for prior to the patient commencing treatment.

\section{Treatment plan}

The plan should detail the advice given, treatments that were agreed on, the duration and frequency of treatments, and details of follow-up and review. If nutraceutical and herbal supplements are recommended, these should be recorded in the prescription history, alongside pharmaceutical treatments. Where the recommended therapies are outside of the scope of conventional healthcare (e.g. yoga therapy), a brief description of the therapy and summary of evidence for effectiveness and safety can be a useful knowledge transfer exercise. A key aspect of collaborative care is the sharing of the treatment plan with all of the treating team.

\section{Efficacy and safety of nutraceuticals and herbal medicines}

While detailed discussion of the evidence of individual nutraceuticals and phytoceuticals (herbal medicines) are outside the auspices of this review, readers are advised to consult these recent reviews of the area $[66,108,109]$. In summation, there are a range of natural products which have supportive RCT or meta-analytic level of efficacy, however quality and standardisation can be an issue, especially in regards to phytoceuticals. In respect to safety, a recent meta-review of nutraceuticals for mental health disorders (including polyunsaturated fatty acids (PUFAs), vitamins, minerals, antioxidants, amino acids and pre/probiotic supplements) reported that all nutrient supplements included in the review did not result in serious adverse effects or contraindications with psychiatric medications [108]. A number of important supplement-drug interactions however should be considered prior to prescription. A collaborative care approach, which includes a shared medical record and improved interprofessional communication, can facilitate early identification of potential adverse events and prevention of drug-supplement interactions. An important advantage of collaborative care settings over conventional care models is the opportunity for shared learning between conventionally trained physicians and other allied health practitioners about appropriate safe uses of a wide range of conventional and integrative modalities.

\section{Psychological therapies}

Psychological therapies are a vital component of collaborative care in mental health, and are advocated to be provided by those with adequate high-level training. For example, the most evidence-based approach, cognitive behaviour therapy, is based on a premise that maladaptive cognitions are the cause of emotional distress and behavioural problems and that change can be mobilised through various cognitive (i.e. cognitive 
restructuring) and behavioural (i.e. pleasant activities) strategies that are effective across a range of mental health conditions and comorbid presentations [110].

\section{Assessment tools}

A systematic approach to follow-up is often a key component in high quality collaborative care. The judicious use of anthropometric measures, physical activity tracking (using fitness trackers or accelerometers), and pathology, are highly recommended. In particular, regular cardiometabolic monitoring is essential. The use of validated Patient Reported Outcome and Experience Measures (PROMS and PREMS) are also recommended in order to objectively assess any change in clinical condition. These would depend on the individual mental health and physical conditions, but can additionally include generic measures of quality of life such as the EQ-5D [111] or PROMIS 29 [112]. Assessing the patient's main clinical need can be undertaken through use of a tool such as the MYCAW [105]. Other measures that can be helpful include measures of patient activation (the Patient Activation Measure) [113] and chronic disease self-efficacy (the Self-Efficacy for Managing Chronic Disease Scale) [114].

Additionally, at all clinical encounters, adverse events should be enquired about and documented. It may also be necessary to monitor for and manage metabolic and other sequelae from pharmaceutical treatments. A care coordinator can play an important role in organising regular review based on clinical pathways and algorithms, and importantly in following up patients who do not attend scheduled follow-up.

\section{Patient education}

In many collaborative care models, patient education is a key component. This can be delivered in several formats: written information, via mobile applications, or video (online or telehealth formats) can enhance the delivery of collaborative care. Written information on the benefits and risks of pharmaceuticals, nutraceuticals and phytoceuticals and on the importance of adhering to treatment and of regular monitoring of physical health are also recommended. Shared Medical Appointments or Group Medical Visits are emerging as a novel way to deliver healthcare [115]. Education about lifestyle changes can be combined with the shared medical appointment, and the addition of a group integrative therapy such as group acupuncture, mindfulness meditation, yoga therapy or tai chi may also be of benefit.

\section{Facilitating team-based care}

Collaborative care improves on conventional healthcare by using a multidisciplinary approach and improving communication between health care professionals caring for a patient. The healthcare team may include a practice nurse or mental health nurse, primary care practitioner/ general practitioner, psychiatrist, psychologists, other medical specialists e.g. neurologist/endocrinologist/cardiologist, allied health practitioners e.g. dieticians, exercise physiologists, physiotherapists, drug and alcohol services. Integrative collaborative care may also include complementary therapy practitioners on the healthcare team, where appropriate, such as yoga therapists or those specialised in natural product prescription. It is important that scope of practice for each practitioner is carefully delineated, and that appropriate credentialing of practitioners is implemented. Particular care may need to be taken in the case of health professions that do not have mandatory regulatory standards.

- Care coordination is a common component in collaborative care, and involves a designated person ensuring that the needs of the patient are met, and access to relevant services are facilitated [116, 117]. This includes coordinating referrals that are required to provide holistic care. The role of care coordinator or case manager could potentially be held by a practice nurse, mental health nurse, or health advocate.

- Enhancing interprofessional communication is an essential component of collaborative care. Utilising a shared medical record wherever possible is highly recommended. Sharing of the medical record and treatment plan may be facilitated through a universal patient-controlled health record, for example in Australia using the MyHealthRecord. Communication with other team members can be facilitated through "warm handovers" and secure messaging. In some cases, case conferencing may be useful, or joint consultations with the patient. The authors also see the value in opportunistic (discrete and de-identified) "corridor consultations", which are facilitated by colocation of healthcare providers. Regular multidisciplinary team meetings to discuss new or complex cases are also recommended.

- Other interventions that can enhance team-based care include "shadowing", experiential sessions (e.g. trialling yoga therapy or exercise physiology personally), and in-service sessions with practitioners presenting information on their modality to the team.

- Physical integration of primary and secondary healthcare can be helpful, for example having an on-site psychiatrist consult in the same centre as the primary care practitioner and allied/complementary health 
practitioners once a week, including the opportunity to hold joint case-conferencing.

\section{Research considerations}

Whilst there is growing evidence within each of the modalities of adjunctive treatment above, there is also great potential for future research, in order to better inform evidence-based mental healthcare for people with physical co-morbidities. Our recommendations for future research priorities are as follows:

1. Research that focusses on a range of service delivery elements are needed, including: improving access to mental health services (particularly in public health systems); improving mental health literacy (for providers/patients/carers); identifying barriers to high quality collaborative care for people with mental and physical co-morbidities; supporting health service providers; delivering a person-centred approach;

2. Research in this area should involve the community and patient/consumer-informed study designs;

3. Physical Activity (PA): whilst there is now robust evidence from meta-analyses of RCTs supporting the use of exercise interventions in the treatment of mental illness, there is now a need to assess if PA interventions can effectively prevent mental illness from arising in at risk population. Already, there is extensive evidence from population studies that greater levels of PA are associated with reduced mental health risk, however whether or not PA interventions can reduce the incidence of mental illness in the real-world settings has yet to be established.

4. Dietary interventions: Initial trials for dietary interventions in those with moderate depression have presented promising results, supported by RCTs showing reductions in depressive symptomology across the general population from dietary improvement. However, further replication (using more robust controls) and expansion on the research around dietary interventions as an adjunctive treatment for those with diagnosed psychiatric conditions is needed.

5. Nutraceuticals/Phytoceuticals: The emergent evidence for a range of natural products exist. A range of these should be further explored in future trials, particularly in young people in the early stages of mental illness. Alongside this, further implementation research is required to establish how supplements with existing strong evidence for efficacy (such as high-dose EPA for major depression) can be integrated into standard care.

6. Mind-Body Therapies: there is growing interest in mindfulness, yoga, and other mind-body activities for promoting mental health. Despite some preliminary evidence of beneficial effects compared to treatment-as-usual, the extent to which mind-body therapies exceed the general intervention effects (i.e. compared to relaxation control conditions, or light physical activity such as walking) has yet to be demonstrated. Furthermore, benefits in those with severe psychiatric conditions have not been widely assessed. Given the feasibility and acceptability of mind-body treatments, further research is urgently warranted to assess how the potential benefits can be maximized and implemented in clinical care. One particular format for this approach is via video 'Telehealth' delivery which may allow for greater patient accessibility and compliance.

\section{Summary}

Leveraging collaborative care in primary care settings and providing individualized evidence-informed integrative interventions that address mental health needs has the potential to improve both psychiatric and physical health outcomes. Due to the challenges outlined, it is now urgent that a more integrated patient-centred approach occur within the field of mental health, with a particular focus also on physical health. Both are intimately connected and influence each other, thus an approach which considers both body and mind as one interrelated nexus. While research underpinning such an approach, and the potential down-stream psychosocial and economic benefits are nascent, as outlined above, there is genuine promise in this approach, and thereby continuing development of this model is advocated. The end result will likely be more cost-effective solutions to complex mental health problems and enhanced overall health of the population.

\section{Acknowledgements \\ CE is supported by an endowment from the Jacka Foundation of Natural Therapies. JL was supported by a Blackmores Institute Visiting Fellowship to the NICM Health Research Institute. JF was supported during part of this manuscript's development by a Blackmores Institute Fellowship, JS is sup- ported by an NHMRC Clinical Research Fellowship (APP1125000).}

\section{Authors' contribution}

$J \mathrm{~L}$ conceived of the manuscript and wrote the first draft. CE led the subsequent drafts of the manuscript. All authors reviewed the manuscript and revised it for important intellectual content. All authors read and approved the final manuscript.

Funding

No funding was received to produce this manuscript.

Availability of data and materials

Not applicable.

Ethics approval and consent to participate

Not applicable. 


\section{Consent for publication \\ Not applicable.}

\section{Competing interests}

CE declares that she is a practising GP and acupuncturist and the Director of an integrative healthcare centre. JS has received either presentation honoraria, travel support, clinical trial grants, book royalties, or independent consultancy payments from: Integria Healthcare \& MediHerb, Pfizer, Scius Health, Key Pharmaceuticals, Australian Natural Therapies Group, Taki Mai, FIT-BioCeuticals, Blackmores, Soho-Flordis, Healthworld, HealthEd, HealthMasters, Kantar Consulting, Grunbiotics, Australian Natural Therapeutics Group, Research Reviews, Elsevier, Chaminade University, International Society for Affective Disorders, Complementary Medicines Australia, SPRIM, Terry White Chemists, ANS, Society for Medicinal Plant and Natural Product Research, Sanofi-Aventis, Omega-3 Centre, the National Health and Medical Research Council, CR Roper Fellowship. As a medical research institute, NICM Health Research Institute receives research grants and donations from foundations, universities, government agencies, and industry. Sponsors and donors provide untied funding for work to advance the vision and mission of the Institute. The project that is the subject of this article was not undertaken as part of a contractual relationship with any donor or sponsor.

\section{Author details \\ ${ }^{1}$ NICM Health Research Institute, Western Sydney University, Penrith, NSW 2751, Australia. ${ }^{2}$ School of Psychology and Translational Health Research Institute, Western Sydney University, Penrith, Australia. ${ }^{3}$ IMPACT, Food \& Mood Centre, Deakin University, Barwon Health, Geelong, Australia. ${ }^{4}$ Professorial Unit, Department of Psychiatry, The University of Melbourne, Melbourne, Australia.}

Received: 18 June 2020 Accepted: 28 October 2020 Published online: 11 November 2020

\section{References}

1. Organization WH. The global burden of disease: 2004 update. Geneva: World Health Organization; 2008.

2. Organization WH. Mental health action plan 2013-2020. Geneva: WHO; 2013

3. Mental disorders. https://www.who.int/news-room/fact-sheets/detail/ mental-disorders.

4. WHO. Addressing comorbidity between mental disorders and major noncommunicable diseases. Geneva: WHO Regional Office for Europe; 2017.

5. WHO. Depression and other common mental disorders global health estimates. Geneva: World Health Organization; 2017.

6. van Oudheusden LJ, Meynen G, van Balkom AJ. Psychiatric comorbidity: theoretical and clinical dilemmas. Tijdschrift voor psychiatrie. 2015:57(9):664-71.

7. The state of mental health in America 2017. https://www.mhanationa l.org/sites/default/files/2017\%20MH\%20in\%20America\%20Full.pdf.

8. David AS, Kopelman MD. Neuropsychology in Relation to Psychiatry. In: David D, Fleminger S, Kopelman M, Lovestone S, Mellers J, editors. Lishman's organic psychiatry: a textbook of neuropsychiatry. Oxford: Wiley-Blackwell; 2009. p. 29-102.

9. Firth J, Siddiqi N, Koyanagi A, Siskind D, Rosenbaum S, Galletly C, Allan S, Caneo C, Carney R, Carvalho AF, et al. The lancet psychiatry commission: a blueprint for protecting physical health in people with mental illness. Lancet Psychiatry. 2019;6(8):675-712

10. Reilly S, Planner C, Gask L, Hann M, Knowles S, Druss B, Lester H. Collaborative care approaches for people with severe mental illness. Cochrane Database Syst Rev. 2013;2013:11.

11. Kritharides $L$, Chow V, Lambert TJ. Cardiovascular disease in patients with schizophrenia. The Medical journal of Australia. 2017;206(2):91-5.

12. Kang H-J, Kim S-Y, Bae K-Y, Kim S-W, Shin I-S, Yoon J-S, Kim J-M Comorbidity of depression with physical disorders: research and clinical implications. Chonnam Med J. 2015;51(1):8-18.

13. Saari K, Koponen H, Laitinen J, Jokelainen J, Lauren L, Isohanni M, Lindeman S. Hyperlipidemia in persons using antipsychotic medication: a general population-based birth cohort study. J Clin Psychiatry. 2004;65(4):547-50.

14. Correll MDEH, Bobes CU, Cetkovich-Bakmas J, Cohen M, Asai D, Detraux I, Gautam J, Moller S, Ndetei HJ. DM et al: Physical illness in patients with severe mental disorders. I. Prevalence, impact of medications and disparities in health care. World Psychiatry. 2011;10(1):52-77.

15. Berk M, Williams LJ, Jacka FN, O'Neil A, Pasco JA, Moylan S, Allen NB, Stuart AL, Hayley AC, Byrne ML, et al. So depression is an inflammatory disease, but where does the inflammation come from? BMC Med. 2013;11:200.

16. Ng F, Berk M, Dean O, Bush Al. Oxidative stress in psychiatric disorders: evidence base and therapeutic implications. Int J Neuropsychopharmacol. 2008:11(6):851-76.

17. Cryan JF, O'Riordan KJ, Cowan CSM, Sandhu KV, Bastiaanssen TFS, Boehme M, Codagnone MG, Cussotto S, Fulling C, Golubeva AV, et al. The microbiota-gut-brain axis. Physiol Rev. 2019;99(4):1877-2013.

18. Firth J, Veronese N, Cotter J, Shivappa N, Hebert JR, Ee C, Smith L, Stubbs B, Jackson SE, Sarris J. What is the role of dietary inflammation in severe mental illness? A review of observational and experimental findings. Front Psychiatry. 2019;10:350.

19. Sotelo JL, Musselman D, Nemeroff C. The biology of depression in cancer and the relationship between depression and cancer progression. Int Rev Psychiatry. 2014;26(1):16-30.

20. Roberts SH, Bailey JE. Incentives and barriers to lifestyle interventions for people with severe mental illness: a narrative synthesis of quantitative, qualitative and mixed methods studies. J Adv Nurs. 2011;67(4):690-708.

21. Garrido S, Millington C, Cheers D, Boydell K, Schubert E, Meade T, Nguyen QV. What works and what doesn't? A systematic review of digital mental health interventions for depression and anxiety in young people. Front Psychiatry. 2019;10:759.

22. Boulos C, Salameh P, Barberger-Gateau P. Social isolation and risk for malnutrition among older people. Geriatr Gerontol Int. 2017;17(2):286-94.

23. Ehsan AM, De Silva MJ. Social capital and common mental disorder: a systematic review. J Epidemiol Community Health. 2015;69(10):1021-8.

24. Grassi L, Caruso R, Hammelef K, Nanni MG, Riba M. Efficacy and safety of pharmacotherapy in cancer-related psychiatric disorders across the trajectory of cancer care: a review. Int Rev Psychiatry. 2014;26(1):44-62.

25. Ciaramella A, Spiegel D. Psychiatric disorders among cancer patients. Handb Clin Neurol. 2012;106:557-72.

26. Gabilondo A, Alonso-Moran E, Nuno-Solinis R, Orueta JF, Iruin A. Comorbidities with chronic physical conditions and gender profiles of illness in schizophrenia. Results from PREST, a new health dataset. J Psychosom Res. 2017;93:102-9.

27. Ko A, Kim K, Sik Son J, Park HY, Park SM. Association of pre-existing depression with all-cause, cancer-related, and noncancer-related mortality among 5-year cancer survivors: a population-based cohort study. Scientific reports. 2019;9(1):18334.

28. Yohannes AM, Willgoss TG, Baldwin RC, Connolly MJ. Depression and anxiety in chronic heart failure and chronic obstructive pulmonary disease: prevalence, relevance, clinical implications and management principles. Int J Geriatr Psychiatry. 2010;25(12):1209-21.

29. Raic M. Depression and heart diseases: leading health problems. Psychiatria Danubina. 2017:29(Suppl 4):770-7.

30. Musselman DL, Betan E, Larsen H, Phillips LS. Relationship of depression to diabetes types 1 and 2: epidemiology, biology, and treatment. Biol Psychiatry. 2003;54(3):317-29.

31. Forrest KY, Becker DJ, Kuller LH, Wolfson SK, Orchard TJ. Are predictors of coronary heart disease and lower-extremity arterial disease in type 1 diabetes the same? A prospective study. Atherosclerosis. 2000;148(1):159-69.

32. Aucoin M, Bhardwaj S. Generalized anxiety disorder and hypoglycemia symptoms improved with diet modification. Case Rep Psychiatry. 2016;2016:7165425.

33. Bhattacharya R, Shen C, Sambamoorthi U. Excess risk of chronic physical conditions associated with depression and anxiety. BMC Psychiatry. 2014;14(1):10.

34. Jaroudi W, Garami J, Garrido S, Hornberger M, Keri S, Moustafa AA. Factors underlying cognitive decline in old age and Alzheimer's disease: the role of the hippocampus. Rev Neurosci. 2017;28(7):705-14. 
35. Gustavson KA, Alexopoulos GS, Niu GC, McCulloch C, Meade T, Areán PA. Problem-solving therapy reduces suicidal ideation in depressed older adults with executive dysfunction. The American Journal of Geriatric Psychiatry. 2016;24(1):11-7.

36. Antidepressants. Do they 'work' or don't they? https://www.scientific american.com/article/antidepressants-do-they-work-or-dont-they/.

37. Stafford MR, Mayo-Wilson E, Loucas CE, James A, Hollis C, Birchwood $M$, Kendall T. Efficacy and safety of pharmacological and psychological interventions for the treatment of psychosis and schizophrenia in children, adolescents and young adults: a systematic review and metaanalysis. PLoS ONE. 2015;10(2):e0117166.

38. Hartling L, Abou-Setta AM, Dursun S, Mousavi SS, Pasichnyk D, Newton AS. Antipsychotics in adults with schizophrenia: comparative effectiveness of first-generation versus second-generation medications: a systematic review and meta-analysis. Ann Intern Med. 2012;157(7):498-511.

39. Fournier JC, DeRubeis RJ, Hollon SD, Dimidjian S, Amsterdam JD, Shelton RC, Fawcett J. Antidepressant drug effects and depression severity: a patient-level meta-analysis. Jama. 2010;303(1):47-53.

40. Thase ME. STEP-BD and bipolar depression: what have we learned? Curr Psychiatry Rep. 2007;9(6):497-503.

41. Velligan DI, Weiden PJ, Sajatovic M, Scott J, Carpenter D, Ross R, Docherty JP. The expert consensus guideline series: adherence problems in patients with serious and persistent mental illness. J Clin Psychiatry. 2009;70(Suppl 4):1-46. quiz 47-48.

42. Herrmann N, Chau SA, Kircanski I, Lanctot KL. Current and emerging drug treatment options for Alzheimer's disease: a systematic review. Drugs. 2011;71(15):2031-65.

43. Kirsch I, Deacon BJ, Huedo-Medina TB, Scoboria A, Moore TJ, Johnson BT. Initial severity and antidepressant benefits: a meta-analysis of data submitted to the Food and Drug Administration. PLoS Med. 2008;5(2):e45.

44. Dubin WR. Clinical practices that lead to treatment resistance (Abstract 81D, Symposium 81). In: Jayaram G. American psychiatric association 2004 annual meeting. New York: American Psychiatric Association; 2004: 89.

45. Bhui K. Treatment resistant mental illnesses. Br J Psychiatry. 2018;210(6):443-4.

46. Muller HHO, Moeller S, Lucke C, Lam AP, Braun N, Philipsen A. Vagus nerve stimulation (VNS) and other augmentation strategies for therapyresistant depression (TRD): review of the evidence and clinical advice for use. Front NeuroSci. 2018;12:239.

47. Center for Clinical Decisions and Communications Science. Nonpharmacological versus pharmacological treatment for patients with major depressive disorder: Current state of the evidence. https://www.ncbi. nlm.nih.gov/books/NBK396521/.

48. Barnes PM, Bloom B, Nahin RL. Complementary and alternative medicine use among adults and children: United States, 2007. National health statistics reports. 2008;12:1-23.

49. Beck A, Crain AL, Solberg LI, Unutzer J, Glasgow RE, Maciosek MV, Whitebird R. Severity of depression and magnitude of productivity loss. Ann Fam Med. 2011;9(4):305-11.

50. Laxman KE, Lovibond KS, Hassan MK. Impact of bipolar disorder in employed populations. Am J Manag Care. 2008;14(11):757-64.

51. Barbato A. Schizophrenia and public health. Geneva: Division of Mental Health and Prevention of Substance Abuse, World Health Organization; 1998.

52. Depression: the treatment and management of depression in adults (update). National Clinical Practice Guideline 90. https://www.nice.org. uk.

53. (NICE) NIfHaCE. Repetitive transcranial magnetic stimulation for depression: Interventional procedures guidance [IPG542]. 2015.

54. Ijaz S, Davies P, Williams CJ, Kessler D, Lewis G, Wiles N. Psychological therapies for treatment-resistant depression in adults. Cochrane database of systematic reviews. 2018;2015:5.

55. Borsboom D. A network theory of mental disorders. World Psychiatry. 2017; 16(1):5-13.

56. Newby JM, McKinnon A, Kuyken W, Gilbody S, Dalgleish T. Systematic review and meta-analysis of transdiagnostic psychological treatments for anxiety and depressive disorders in adulthood. Clin Psychol Rev. 2015;40:91-110.
57. Henderson DC. Managing weight gain and metabolic issues in patients treated with atypical antipsychotics. J Clin Psychiatry. 2008;69(2):e04.

58. National Collaborating Centre for Mental Health. Depression in adults with a chronic physical health problem: recognition and management. NICE Clinical Guideline CG91. NICE; 2009.

59. Yatham LN, Kennedy SH, Parikh SV, Schaffer A, Bond DJ, Frey BN, Sharma V, Goldstein BI, Rej S, Beaulieu S, et al. Canadian Network for Mood and Anxiety Treatments (CANMAT) and International Society for Bipolar Disorders (ISBD) 2018 guidelines for the management of patients with bipolar disorder. Bipolar disorders. 2018;20(2):97-170.

60. Galletly C, Castle D, Dark F, Humberstone V, Jablensky A, Killackey E, Kulkarni J, McGorry P, Nielssen O, Tran N. Royal Australian and New Zealand College of Psychiatrists clinical practice guidelines for the management of schizophrenia and related disorders. Aust N Z J Psychiatry. 2016;50(5):410-72.

61. Association AP. The American Psychiatric Association Practice Guideline for the Treatment of Patients with Schizophrenia. Draft; undergoing copyediting edn; 2019.

62. Rhee TG, Evans RL, McAlpine DD, Johnson PJ. Racial/ethnic differences in the use of complementary and alternative medicine in US adults with moderate mental distress: results from the 2012 National Health Interview Survey. Journal of primary care community health. 2017;8(2):43-54.

63. Seet V, Abdin E, Vaingankar JA, Shahwan S, Chang S, Lee B, Chong SA, Subramaniam M. The use of complementary and alternative medicine in a multi-ethnic Asian population: results from the 2016 Singapore Mental Health Study. BMC Complementary Medicine Therapies. 2020;20(1):1-10.

64. Goodrich DE, Kilbourne AM, Nord KM, Bauer MS. Mental health collaborative care and its role in primary care settings. Current psychiatry reports. 2013;15(8):383.

65. Sarris J, O'Neil A, Coulson CE, Schweitzer I, Berk M. Lifestyle medicine for depression. BMC Psychiatry. 2014;14(1):107.

66. Sarris J, Murphy J, Mischoulon D, Papakostas Gl, Fava M, Berk M, Ng $\mathrm{CH}$. Adjunctive nutraceuticals for depression: a systematic review and meta-analyses. Am J Psychiatry. 2016;173(6):575-87.

67. Sarris J, Sinclair J, Karamacoska D, Davidson M, Firth J. Medicinal cannabis for psychiatric disorders: a clinically-focused systematic review. BMC Psychiatry. 2020;20(1):24.

68. Purohit MP, Wells RE, Zafonte R, Davis RB, Yeh GY, Phillips RS. Neuropsychiatric symptoms and the use of mind-body therapies. J Clin Psychiatry. 2013;74(6):e520.

69. Ashdown-Franks G, Firth J, Carney R, Carvalho AF, Hallgren M, Koyanagi A, Rosenbaum S, Schuch FB, Smith L, Solmi M. Exercise as medicine for mental and substance use disorders: a meta-review of the benefits for neuropsychiatric and cognitive outcomes. Sports Medicine. 2019;2019:1-20.

70. Firth J, Marx W, Dash S, Carney R, Teasdale SB, Solmi M, Stubbs B, Schuch FB, Carvalho AF, Jacka F, et al. The effects of dietary improvement on symptoms of depression and anxiety: a meta-analysis of randomized controlled trials. Psychosom Med. 2019;81(3):265-80,

71. Taylor G, McNeill A, Girling A, Farley A, Lindson-Hawley N, Aveyard P. Change in mental health after smoking cessation: systematic review and meta-analysis. BMJ. 2014;348:g1151.

72. Carriere K, Khoury B, Gunak MM, Knauper B. Mindfulness-based interventions for weight loss: a systematic review and meta-analysis. Obesity Rev. 2018;19(2):164-77.

73. Katterman SN, Kleinman BM, Hood MM, Nackers LM, Corsica JA. Mindfulness meditation as an intervention for binge eating, emotional eating, and weight loss: a systematic review. Eat Behav. 2014;15(2):197-204.

74. Rogers JM, Ferrari M, Mosely K, Lang CP, Brennan L. Mindfulness-based interventions for adults who are overweight or obese: a metaanalysis of physical and psychological health outcomes. Obesity Rev. 2017;18(1):51-67.

75. Ruffault A, Czernichow S, Hagger MS, Ferrand M, Erichot N, Carette C, Boujut $E$, Flahault $C$. The effects of mindfulness training on weightloss and health-related behaviours in adults with overweight and obesity: a systematic review and meta-analysis. Obesity Res Clin Pract. 2017;11(5):90-111. 
76. Butler M, Kane RL, McAlpine D, Kathol RG, Fu SS, Hagedorn H, Wilt TJ. Integration of mental health/substance abuse and primary care. Evid Rep Technol Assess. 2008;173:1-362.

77. Camacho EM, Davies LM, Hann M, Small N, Bower P, Chew-Graham C, Baguely C, Gask L, Dickens CM, Lovell K, et al. Long-term clinical and cost-effectiveness of collaborative care (versus usual care) for people with mental-physical multimorbidity: cluster-randomised trial. Br J Psychiatry. 2018;213(2):456-63.

78. Unutzer J, Katon W, Callahan CM, Williams JW Jr, Hunkeler E, Harpole L, Hoffing M, Della Penna RD, Noel PH, Lin EH, et al. Collaborative care management of late-life depression in the primary care setting: a randomized controlled trial. JAMA. 2002;288(22):2836-45.

79. Gilbody S, Bower P, Whitty P. Costs and consequences of enhanced primary care for depression: systematic review of randomised economic evaluations. Br J Psychiatry. 2006;189:297-308.

80. Simon G. Collaborative care for mood disorders. Curr Opin Psychiatry. 2009;22(1):37-41

81. Reilly S, Planner C, Gask L, Hann M, Knowles S, Druss B, Lester H. Collaborative care approaches for people with severe mental illness. Cochrane Datab Syst Rev. 2013:11:9531.

82. Woltmann E, Grogan-Kaylor A, Perron B, Georges H, Kilbourne AM, Bauer MS. Comparative effectiveness of collaborative chronic care models for mental health conditions across primary, specialty, and behavioral health care settings: systematic review and meta-analysis. Am J Psychiatry. 2012;169(8):790-804.

83. Katon W, Russo J, Lin EH, Schmittdiel J, Ciechanowski P, Ludman E, Peterson D, Young B, Von Korff M. Cost-effectiveness of a multicondition collaborative care intervention: a randomized controlled trial. Arch Gen Psychiatry. 2012;69(5):506-14.

84. Arean PA, Ayalon L, Hunkeler E, Lin EH, Tang L, Harpole L, Hendrie H, Williams JW Jr, Unutzer J. Improving depression care for older, minority patients in primary care. Medical care. 2005;43(4):381-90.

85. Ell K, Katon W, Cabassa LJ, Xie B, Lee PJ, Kapetanovic S, Guterman J. Depression and diabetes among low-income Hispanics: design elements of a socioculturally adapted collaborative care model randomized controlled trial. Int J Psychiatry Med. 2009;39(2):113-32.

86. Ell K, Aranda MP, Xie B, Lee PJ, Chou CP. Collaborative depression treatment in older and younger adults with physical illness: pooled comparative analysis of three randomized clinical trials. The American journal of geriatric psychiatry: official journal of the American Association for Geriatric Psychiatry. 2010;18(6):520-30.

87. Ell K, Katon W, Xie B, Lee PJ, Kapetanovic S, Guterman J, Chou CP. Collaborative care management of major depression among low-income, predominantly Hispanic subjects with diabetes: a randomized controlled trial. Diabetes Care. 2010;33(4):706-13.

88. Unutzer J, Katon WJ, Fan M-Y, Schoenbaum MC, Lin EHB, Della Penna $\mathrm{RD}$, Powers D. Long-term cost effects of collaborative care for late-life depression. Am J Manag Care. 2008;14(2):95-100.

89. Johnson JA, Lier DA, Soprovich A, AI Sayah F, Qiu W, Majumdar SR. Cost-Effectiveness Evaluation of Collaborative Care for Diabetes and Depression in Primary Care. Am J Prev Med. 2016;51(1):e13-20.

90. Katon WJ, Roy-Byrne P, Russo J, Cowley D. Cost-effectiveness and cost offset of a collaborative care intervention for primary care patients with panic disorder. Arch Gen Psychiatry. 2002;59(12):1098-104.

91. Druss BG, von Esenwein SA, Compton MT, Zhao L, Leslie DL. Budget impact and sustainability of medical care management for persons with serious mental illnesses. Am J Psychiatry. 2011;168(11):1171-8.

92. Grypma L, Haverkamp R, Little S, Unutzer J. Taking an evidence-based model of depression care from research to practice: making lemonade out of depression. Gen Hosp Psychiatry. 2006;28(2):101-7.

93. Reiss-Brennan B, Briot PC, Savitz LA, Cannon W, Staheli R. Cost and quality impact of Intermountain's mental health integration program. J Healthc Manag/Am Coll Healthc Exec. 2010;55(2):97-113. discussion 113-114.

94. Levine S, Unutzer J, Yip JY, Hoffing M, Leung M, Fan MY, Lin EH, Grypma L, Katon W, Harpole LH, et al. Physicians' satisfaction with a collaborative disease management program for late-life depression in primary care. Gen Hosp Psychiatry. 2005;27(6):383-91.

95. Introduction. https://imconsortium.org/about/introduction/.
96. Herman PM, Craig BM, Caspi O. Is complementary and alternative medicine (CAM) cost-effective? A systematic review. BMC Complement Altern Med. 2005:5:11-1.

97. Pelletier KR, Herman PM, Metz RD, Nelson CF. Health and medical economics applied to integrative medicine. Explore (New York NY). 2010;6(2):86-99.

98. Chatterton ML, Mihalopoulos C, O'Neil A, Itsiopoulos C, Opie R, Castle D, Dash S, Brazionis L, Berk M, Jacka F. Economic evaluation of a dietary intervention for adults with major depression (the "SMILES" trial). BMC Public Health. 2018;18(1):599-9.

99. Segal L, Twizeyemariya A, Zarnowiecki D, Niyonsenga T, Bogomolova S, Wilson A, O'Dea K, Parletta N. Cost effectiveness and cost-utility analysis of a group-based diet intervention for treating major depression-the HELFIMED trial. Nutr Neurosci. 2018:2018:1-9.

100. Goodwin N. Understanding integrated care. Int J Integr Care. 2016;16(4):6-6.

101. Ee C, Templeman K, Grant S, Avard N, de Manincor M, Hunter J. Informing the model of care for an academic integrative healthcare centre: a qualitative study exploring healthcare consumer perspectives. BMC Compl Med Ther. 2020;20(1):58.

102. Ee C, Templeman K, Grant S, Avard N, de Manincor M, Reath J, Hunter J. Informing the model of care for an academic integrative health care center: a qualitative study of primary care stakeholder views. J Altern Compl Med. 2020;12:56.

103. Meade T, Dickens G, Hay P, Sarris J, Schmied V, Smith C, Lake JH, Linnel S, Moustafa A, Weidemann G, et al. Depression, comorbidity and integrative care. Penrith: Western Sydney University; 2019.

104. Starfield B. Primary care: balancing health needs, services, and technology. New York: Oxford University Press; 1998.

105. Paterson C, Thomas K, Manasse A, Cooke H, Peace G. Measure yourself concerns and wellbeing (MYCaW): an individualised questionnaire for evaluating outcome in cancer support care that includes complementary therapies. Complementary Therapies in Medicine. 2007;15(1):38-45.

106. Wasson JH, Ho L, Soloway L, Moore LG. Validation of the what matters index: a brief, patient-reported index that guides care for chronic conditions and can substitute for computer-generated risk models. PloS ONE. 2018;13:2.

107. Stott NC, Rollnick S, Rees M, Pill R. Innovation in clinical method: diabetes care and negotiating skills. Fam Pract. 1995;12(4):413-8.

108. Firth J, Teasdale SB, Allott K, Siskind D, Marx W, Cotter J, Veronese N, Schuch F, Smith L, Solmi M, et al. The efficacy and safety of nutrient supplements in the treatment of mental disorders: a meta-review of meta-analyses of randomized controlled trials. World Psychiatry. 2019;18(3):308-24.

109. Sarris J, Marx W, Ashton M, Ng C, Galvao-Coelho N, Ayati Z, Zhang Z, Kasper S, Ravindran A, Harvey B, et al. Plant-based medicines (Phytoceuticals) in the treatment of psychiatric disorders: a meta-review of meta-analyses of randomized controlled trials. European Neuropsychopharmacology 2020 (In submission).

110. Hofmann SG, Asnaani A, Vonk IJ, Sawyer AT, Fang A. The efficacy of cognitive behavioral therapy: A review of meta-analyses. Cognitive therapy research. 2012;36(5):427-40.

111. Herdman M, Gudex C, Lloyd A, Janssen M, Kind P, Parkin D, Bonsel G, Badia X. Development and preliminary testing of the new five-level version of EQ-5D (EQ-5D-5L). Qual Life Res. 2011;20(10):1727-36.

112. Hays RD, Spritzer KL, Schalet BD, Cella D. PROMIS((R))-29 v2.0 profile physical and mental health summary scores. Qual Life Res. 2018;27(7):1885-91.

113. Hibbard JH, Stockard J, Mahoney ER, Tusler M. Development of the patient activation measure (PAM): conceptualizing and measuring activation in patients and consumers. Health Services Res. 2004;39(4p1):1005-26.

114. Riehm KE, Kwakkenbos L, Carrier ME, Bartlett SJ, Malcarne VL, Mouthon L, Nielson WR, Poiraudeau S, Nielsen K, Baron M. Validation of the self-efficacy for managing chronic disease scale: a scleroderma patient-centered intervention network cohort study. Arthritis Care Res. 2016;68(8):1195-200.

115. Egger G, Binns A, Cole M, Ewald D, Davies L, Meldrum H, Stevens J, Noffsinger E. Shared medical appointments an adjunct for chronic disease management in Australia? Aust Fam Phys. 2014;43:151-4. 
116. Hannigan B, Simpson A, Coffey M, Barlow S, Jones A. Care coordination as imagined, care coordination as done: findings from a cross-national mental health systems study. Int J Integr Care. 2018;18:3.

117. Schultz EM, McDonald KM. What is care coordination? Int J Care Coordinat. 2014;17(1-2):5-24.

118. Stubbs B, Vancampfort D, Hallgren M, Firth J, Veronese N, Solmi M, Brand S, Cordes J, Malchow B, Gerber M. EPA guidance on physical activity as a treatment for severe mental illness: a meta-review of the evidence and Position Statement from the European Psychiatric Association (EPA), supported by the International Organization of Physical Therapists in Mental Health (IOPTMH). Eur Psychiatry. 2018;54:124-44

119. Schuch FB, Stubbs B, Meyer J, Heissel A, Zech P, Vancampfort D, Rosenbaum S, Deenik J, Firth J, Ward PB. Physical activity protects from incident anxiety: a meta-analysis of prospective cohort studies. Depress Anxiety. 2019;36(9):846-58.

120. Schuch FB, Vancampfort D, Firth J, Rosenbaum S, Ward PB, Silva ES, Hallgren M, Ponce De Leon A, Dunn AL, Deslandes AC. Physical activity and incident depression: a meta-analysis of prospective cohort studies. Am J Psychiatry. 2018;175(7):631-48.

121. Moore SC, Lee I-M, Weiderpass E, Campbell PT, Sampson JN, Kitahara CM, Keadle SK, Arem H, De Gonzalez AB, Hartge P. Association of leisure-time physical activity with risk of 26 types of cancer in 1.44 million adults. JAMA internal medicine. 2016;176(6):816-25.

122. Schmitz KH, Courneya KS, Matthews C, Demark-Wahnefried W, Galvão DA, Pinto BM, Irwin ML, Wolin KY, Segal RJ, Lucia A. American College of Sports Medicine roundtable on exercise guidelines for cancer survivors. Med Sci Sports Exerc. 2010;42(7):1409-26.

123. Patterson $R$, McNamara E, Tainio M, de Sá TH, Smith AD, Sharp SJ, Edwards P, Woodcock J, Brage S, Wijndaele K. Sedentary behaviour and risk of all-cause, cardiovascular and cancer mortality, and incident type 2 diabetes: a systematic review and dose response meta-analysis. Berlin: Springer; 2018.

124. Li J, Siegrist J. Physical activity and risk of cardiovascular disease-a meta-analysis of prospective cohort studies. Int J Environ Res Public Health. 2012;9(2):391-407.

125. Aune D, Norat T, Leitzmann M, Tonstad S, Vatten LJ. Physical activity and the risk of type 2 diabetes: a systematic review and dose-response meta-analysis. Berlin: Springer; 2015.

126. Xu W, Wang HF, Wan Y, Tan C-C, Yu J-T, Tan L. Leisure time physical activity and dementia risk: a dose-response meta-analysis of prospective studies. BMJ open. 2017;7(10):e014706.

127. Hedman-Lagerlöf M, Hedman-Lagerlöf E, Öst L-G. The empirical support for mindfulness-based interventions for common psychiatric disorders: a systematic review and meta-analysis. Psychological medicine. 2018;48(13):2116-29.

128. Goldberg SB, Tucker RP, Greene PA, Davidson RJ, Wampold BE, Kearney DJ, Simpson TL. Mindfulness-based interventions for psychiatric disorders: a systematic review and meta-analysis. Clin Psychol Rev. 2018:59:52-60.

129. Cramer H, Lauche R, Langhorst J, Dobos G. Yoga for depression: a systematic review and meta-analysis. Depress Anxiety. 2013;30(11):1068-83.

130. Cramer H, Lauche R, Klose P, Langhorst J, Dobos G. Yoga for schizophrenia: a systematic review and meta-analysis. BMC Psychiatry. 2013;13(1):32

131. Broderick J, Crumlish N, Waugh A, Vancampfort D. Yoga versus non-standard care for schizophrenia. Cochrane Database Syst Rev. 2017;2017:9.

132. Noordali F, Cumming J, Thompson JL. Effectiveness of Mindfulnessbased interventions on physiological and psychological complications in adults with diabetes: a systematic review. J Health Psychol. 2017;22(8):965-83.

133. Hilton L, Hempel S, Ewing BA, Apaydin E, Xenakis L, Newberry S, Colaiaco B, Maher AR, Shanman RM, Sorbero ME, et al. Mindfulness meditation for chronic pain: systematic review and meta-analysis. Ann Behav Med. 2017:51(2):199-213.

134. Zhang MF, Wen YS, Liu WY, Peng LF, Wu XD, Liu QW. Effectiveness of mindfulness-based therapy for reducing anxiety and depression in patients with cancer: a meta-analysis. Medicine. 2015;94(45):e0897.

135. Wurtzen H, Dalton SO, Elsass P, Sumbundu AD, Steding-Jensen M, Karlsen RV, Andersen KK, Flyger HL, Pedersen AE, Johansen C.
Mindfulness significantly reduces self-reported levels of anxiety and depression: results of a randomised controlled trial among 336 Danish women treated for stage I-III breast cancer. Eur J Cancer. 2013:49(6):1365-73.

136. Lengacher CA, Reich RR, Paterson CL, Ramesar S, Park JY, Alinat C, Johnson-Mallard V, Moscoso M, Budhrani-Shani P, Miladinovic B, et al. Examination of broad symptom improvement resulting from mindfulness-based stress reduction in breast cancer survivors: a randomized controlled trial. J Clin Oncol. 2016;34(24):2827-34.

137. Andersen SR, Wurtzen H, Steding-Jessen M, Christensen J, Andersen KK, Flyger $\mathrm{H}$, Mitchelmore $\mathrm{C}$, Johansen C, Dalton SO. Effect of mindfulnessbased stress reduction on sleep quality: results of a randomized trial among Danish breast cancer patients. Acta Oncol. 2013;52(2):336-44.

138. Haller H, Winkler MM, Klose P, Dobos G, Kummel S, Cramer H. Mindfulness-based interventions for women with breast cancer: an updated systematic review and meta-analysis. Acta Oncol. 2017;56(12):1665-76.

139. Chu P, Gotink RA, Yeh GY, Goldie SJ, Hunink MG. The effectiveness of yoga in modifying risk factors for cardiovascular disease and metabolic syndrome: A systematic review and meta-analysis of randomized controlled trials. Eur J Prev Cardiol. 2016;23(3):291-307.

140. Jayawardena R, Ranasinghe P, Chathuranga T, Atapattu PM, Misra A. The benefits of yoga practice compared to physical exercise in the management of type 2 Diabetes Mellitus: A systematic review and meta-analysis. DiabetesMetabol Syndr. 2018;12(5):795-805.

141. Lyman GH, Greenlee H, Bohlke K, Bao T, DeMichele AM, Deng GE, Fouladbakhsh JM, Gil B, Hershman DL, Mansfield S, et al. Integrative therapies during and after breast cancer treatment: ASCO endorsement of the SIO clinical practice guideline. J Clin Oncol. 2018;36(25):2647-55.

142. Khusid MA, Vythilingam M. The emerging role of mindfulness meditation as effective self-management strategy, part 2: clinical implications for chronic pain, substance misuse, and insomnia. Military Med. 2016;181(9):969-75.

143. Chiesa A, Serretti A. Are mindfulness-based interventions effective for substance use disorders? A systematic review of the evidence. Subst Use Misuse. 2014;49(5):492-512.

144. Francis HM, Stevenson RJ, Chambers JR, Gupta D, Newey B, Lim CK. A brief diet intervention can reduce symptoms of depression in young adults-a randomised controlled trial. PloS ONE. 2019;14(10):e0222768-8.

145. Parletta N, Zarnowiecki D, Cho J, Wilson A, Bogomolova S, Villani A, Itsiopoulos C, Niyonsenga T, Blunden S, Meyer B, et al. A Mediterraneanstyle dietary intervention supplemented with fish oil improves diet quality and mental health in people with depression: a randomized controlled trial (HELFIMED). Nutr Neurosci. 2019;22(7):474-87.

146. Jacka FN, O'Neil A, Opie R, Itsiopoulos C, Cotton S, Mohebbi M, Castle D, Dash S, Mihalopoulos C, Chatterton ML. A randomised controlled trial of dietary improvement for adults with major depression (the 'SMILES'trial). BMC Med. 2017;15(1):23.

147. Dinu M, Pagliai G, Casini A, Sofi F. Mediterranean diet and multiple health outcomes: an umbrella review of meta-analyses of observational studies and randomised trials. Eur J Clin Nutr. 2018;72(1):30-43.

148. Morris MC, Tangney CC, Wang Y, Sacks FM, Bennett DA, Aggarwal NT. MIND diet associated with reduced incidence of Alzheimer's disease. Alzheimers Dement. 2015;11(9):1007-14

149. Menezes R, Rodriguez-Mateos A, Kaltsatou A, Gonzalez-Sarrias A, Greyling A, Giannaki C, Andres-Lacueva C, Milenkovic D, Gibney ER, Dumont J, et al. Impact of flavonols on cardiometabolic biomarkers: a meta-analysis of randomized controlled human Trials to Explore the Role of Inter-Individual Variability. Nutrients. 2017;9:2.

150. Qian F, Liu G, Hu FB, Bhupathiraju SN, Sun Q. Association Between Plant-Based Dietary Patterns and Risk of Type 2 Diabetes: A Systematic Review and Meta-analysis. JAMA Internal Medicine. 2019;179(10):1335-44.

151. Yokoyama Y, Barnard ND, Levin SM, Watanabe M. Vegetarian diets and glycemic control in diabetes: a systematic review and meta-analysis. Cardiovasc Diagn Ther. 2014;4(5):373-82.

152. Esposito K, Maiorino MI, Bellastella G, Chiodini P, Panagiotakos D, Giugliano D. A journey into a Mediterranean diet and type 2 diabetes: a systematic review with meta-analyses. BMJ Open. 2015;5(8):e008222.

153. Martínez-González MA, Gea A, Ruiz-Canela M. The mediterranean diet and cardiovascular health. Circ Res. 2019;124(5):779-98. 
154. Cheng HM, Koutsidis G, Lodge JK, Ashor A, Siervo M, Lara J. Tomato and lycopene supplementation and cardiovascular risk factors: a systematic review and meta-analysis. Atherosclerosis. 2017;257:100-8.

155. Cormick G, Ciapponi A, Cafferata ML, Belizan JM. Calcium supplementation for prevention of primary hypertension. Cochrane Database Syst Rev. 2015;6:10037.

156. Jenkins DJA, Spence JD, Giovannucci EL, Kim YI, Josse R, Vieth R, Blanco Mejia S, Viguiliouk E, Nishi S, Sahye-Pudaruth S, et al. Supplemental Vitamins and Minerals for CVD Prevention and Treatment. J Am Coll Cardiol. 2018;71(22):2570-84.

157. Hu Y, Hu FB, Manson JE. Marine omega-3 supplementation and cardiovascular disease: an updated meta-analysis of 13 randomized controlled trials involving 127477 participants. Journal of the American Heart Association. 2019;8(19):e013543-3.

158. Jafari M, Mousavi SM, Asgharzadeh A, Yazdani N. Coenzyme Q10 in the treatment of heart failure: a systematic review of systematic reviews. Indian Heart J. 2018;70(Suppl 1):111-s117.

159. Wang X, Wu W, Zheng W, Fang X, Chen L, Rink L, Min J, Wang F. Zinc supplementation improves glycemic control for diabetes prevention and management: a systematic review and meta-analysis of randomized controlled trials. Am J Clin Nutr. 2019;110(1):76-90.

160. Poolsup N, Suksomboon N, Kurnianta PDM, Deawjaroen K. Effects of curcumin on glycemic control and lipid profile in prediabetes and type 2 diabetes mellitus: a systematic review and meta-analysis. Plos ONE. 2019;14:4.
161. Zhang SY, Yang KL, Zeng LT, Wu XH, Huang HY. Effectiveness of coenzyme Q10 supplementation for type 2 diabetes mellitus: a systematic review and meta-analysis. Int J Endocrinol. 2018;35:86.

162. Hendijani F, Akbari V. Probiotic supplementation for management of cardiovascular risk factors in adults with type II diabetes: a systematic review and meta-analysis. Clin Nutr. 2018;37(2):532-41.

163. Koutnikova H, Genser B, Monteiro-Sepulveda M, Faurie JM, Rizkalla S, Schrezenmeir J, Clement K. Impact of bacterial probiotics on obesity, diabetes and non-alcoholic fatty liver disease related variables: a systematic review and meta-analysis of randomised controlled trials. BM Open. 2019;9:3

164. Huang H, Chen G, Dong Y, Zhu Y, Chen H. Chromium supplementation for adjuvant treatment of type 2 diabetes mellitus: Results from a pooled analysis. Mol Nutr Food Res. 2018;62:1.

\section{Publisher's Note}

Springer Nature remains neutral with regard to jurisdictional claims in published maps and institutional affiliations.
Ready to submit your research? Choose BMC and benefit from:

- fast, convenient online submission

- thorough peer review by experienced researchers in your field

- rapid publication on acceptance

- support for research data, including large and complex data types

- gold Open Access which fosters wider collaboration and increased citations

- maximum visibility for your research: over 100M website views per year

At BMC, research is always in progress.

Learn more biomedcentral.com/submissions 